\title{
Treatment of aggressive pituitary tumours and carcinomas: results of a European Society of Endocrinology (ESE) survey 2016
}

\author{
Ann McCormack', Olaf M Dekkers², Stephan Petersenn'3, Vera Popovic ${ }^{4}$, Jacqueline Trouillas ${ }^{5}$, Gerald Raverot ${ }^{6}$ \\ and Pia Burman? on behalf of the ESE survey collaborators*
}

${ }^{1}$ St Vincent's Hospital and Garvan Institute of Medical Research, Sydney, Australia, ${ }^{2}$ Department of Internal Medicine (Section Endocrinology) \& Clinical Epidemiology, Leiden University Medical Centre, Leiden, The Netherlands, ${ }^{3}$ ENDOC Center for Endocrine Tumors, Hamburg, Germany, ${ }^{4}$ University Belgrade, Belgrade, Serbia, ${ }^{5}$ Centre de Pathologie et de Biologie Est, Groupement Hospitalier Est, Hospices Civils de Lyon, Bron, France, ${ }^{6}$ Fédération d'Endocrinologie, Groupement Hospitalier Est, Hospices Civils de Lyon, Université de Lyon, Bron, France, and ${ }^{7}$ Department of Endocrinology, Skåne University Hospital Malmö, University of Lund, Lund, Sweden,

*(Details of the ESE survey collaborators are presented in the Acknowledgements section)

Correspondence should be addressed to P Burman

Email

pia.burman@med.lu.se

\begin{abstract}
Objective: To collect outcome data in a large cohort of patients with aggressive pituitary tumours (APT)/carcinomas (PC) and specifically report effects of temozolomide (TMZ) treatment.
\end{abstract}

Design: Electronic survey to ESE members Dec 2015-Nov 2016.

Results: Reports on 166 patients (40 PC, 125 APT, 1 unclassified) were obtained. Median age at diagnosis was 43 (range 4-79) years. $69 \%$ of the tumours were clinically functioning, and the most frequent immunohistochemical subtype were corticotroph tumours (45\%). Ki-67 index did not distinguish APT from PC, median $7 \%$ and $10 \%$ respectively. TMZ was first-line chemotherapy in 157 patients. At the end of the treatment (median 9 cycles), radiological evaluation showed complete response (CR) in 6\%, partial response (PR) in 31\%, stable disease (SD) in $33 \%$ and progressive disease in $30 \%$. Response was more frequent in patients receiving concomitant radiotherapy and TMZ. CR was seen only in patients with low MGMT expression. Clinically functioning tumours were more likely to respond than nonfunctioning tumours, independent of MGMT status. Of patients with CR, PR and SD, 25, 40 and $48 \%$ respectively progressed after a median of 12-month follow-up. Other oncological drugs given as primary treatment and to TMZ failures resulted in PR in $20 \%$.

Conclusion: This survey confirms that TMZ is established as first-line chemotherapeutic treatment of APT/PC. Clinically functioning tumours, low MGMT and concurrent radiotherapy were associated with a better response. The limited long-term effect of TMZ and the poor efficacy of other drugs highlight the need to identify additional effective therapies.

\section{Introduction}

Pituitary tumours are usually benign and slowly growing, but a subset has a more aggressive clinical course. Such tumours often present as invasive macroadenomas and grow rapidly from the outset. Others may initially respond to standard therapy for long periods and only later change their characteristics $(1,2)$. Recently, it was recommended that 'the diagnosis of an aggressive pituitary tumour should be considered in patients with a radiologically invasive tumour and unusually rapid tumour growth rate or clinically relevant tumour growth despite optimal standard therapies (surgery, radiotherapy and conventional medical treatments)' (3). Pituitary

Published by Bioscientifica Ltd. 
carcinomas (PC) are defined by the presence of systemic and/or cerebrospinal metastases (4) and account for $0.2 \%$ pituitary tumours (5). Aggressive pituitary tumours (APT) often exhibit histological features consistent with increased proliferation, Ki-67 indices above 3\%, increased mitotic numbers and p53 expression $(6,7)$. However, the presence of these features does not reliably predict future aggressive behaviour and the prognostic value of these markers is controversial. Two studies taking invasive growth and proliferative markers into account found that tumours exhibiting both criteria had a higher rate of progression/recurrence at follow-up $(8,9)$.

Older chemotherapy regimes typically have limited efficacy; at the most, partial regression or transient stabilisation is achieved (1). Two-thirds of patients are deceased within 12 months of carcinoma diagnosis (10, $11,12)$. Recently, life expectancy in patients with locally aggressive pituitary tumours (APT) was also found to be markedly reduced $(13,14)$.

Temozolomide (TMZ) is a peroral alkylating chemotherapeutic drug approved for treatment of glioblastomas (15). TMZ methylates DNA resulting in irreversible DNA damage and cell death. A DNA repair enzyme, O6-methylguanine DNA methyltransferase (MGMT), counteracts the effect of TMZ by removing added methyl groups. The clinical experience with TMZ in APT has grown over the past ten years since the initial successful reports were published in $2006(16,17,18)$. Earlier small series reported about 75\% regression rates. Subsequent larger studies, still with limited number of patients: 13 (19), 24 (2), 31 (13) and 41 (14) patients have described lower response rates, about $45 \%$, likely reflecting an early publication bias of patients with successful outcomes. In most cases, TMZ has been used as a single agent, others have used TMZ in combination with other drugs, such as capecitabine (20) or concurrent with radiotherapy $(21,22,23)$, which is the standard treatment for glioblastomas (15). Whether such combinations result in an improved outcome in patients with APT, compared to monotherapy, has not been ascertained. In series with longer follow-up after TMZ discontinuation, many pituitary tumours have been found to eventually recur $(2,13,14)$. The role of a second course of TMZ, vs other chemotherapy regimes, novel drugs interfering with growth receptors/growth receptor signalling pathways and/or peptide receptor radionuclide therapy in this scenario remains to be established.

The purpose of the present survey was to collect clinical and treatment outcome data in a large number of patients with APT and PC and specifically to report the experience with TMZ as monotherapy or concomitant with other treatments, and the use of other drugs in TMZ non-responders. Other aims were to identify predictors of response to treatment and to obtain more information as to what extent pathological markers can predict aggressive tumour behaviour.

\section{Methods}

A patient survey developed by the task force on Aggressive Pituitary Tumours, a task force appointed by the European Society of Endocrinology (ESE), was made available for download at the ESE homepage 2015-2016. ESE members were alerted of the survey via email from ESE, and in addition, larger pituitary centres were contacted by the task force members. Participants were requested to fill in a predefined form for patients with APT and submit to the ESE office.

No specific criteria were set in advance for selection and inclusion of patients in the survey in order to collect information on how APTs were defined in clinical practice and to gather a broad and comprehensive experience with the use of TMZ and other agents. Patient demographics, tumour subtype (hormonal immunostaining), tumour size and grade at diagnosis, prior treatments (surgery, radiotherapy, standard medical treatments), clinical features associated with aggressive tumour behaviour and pathological tumour markers (Ki-67 index, numbers of mitoses/per 10 HPFs, p53 immunodetection and MGMT), as assessed by the local laboratories were asked for. Details of treatments given as first- and second-line regimes, outcome and side effects were requested. Following compilation of initial survey results, an additional focused set of information aimed at clarifying data and gathering further follow-up was sent out to participating ESE members throughout 2016 with final closure of case submission in November 2016 (Fig. 1).

Overall response to drugs was assessed by radiological criteria according to MRI imaging at the completion of treatment or for patients still on treatment at last

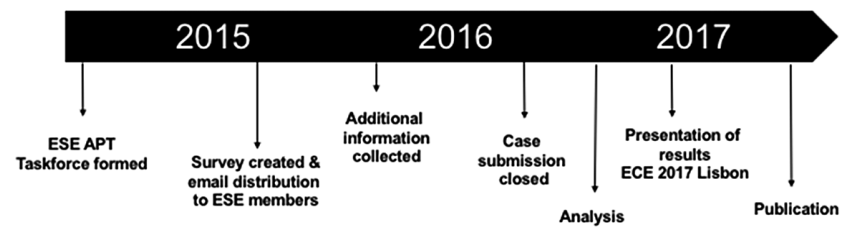

Figure 1

Outline of the ESE survey procedure. 
follow-up. A complete response (CR) was defined as no visible tumour, partial response (PR) as at least $30 \%$ tumour regression, stable disease (SD) as less 30\% regression but no more than $10 \%$ tumour size increase, and progressive disease (PD) as more than $10 \%$ tumour size increase or demonstration of new metastatic deposits. In clinically functioning tumours, complete biochemical response was defined as normalisation of hormone levels, PR as more than $20 \%$ reduction in hormone, stable disease less then but no more than $20 \%$ change in hormone and PD as more than $20 \%$ increase in hormone levels. MGMT immunohistochemical expression was categorised into low $(<10 \%$ positive cells), intermediate $(10-50 \%$ positive cells) and high ( $>50 \%$ positive cells). Data on MGMT methylation assessed by PCR $(n=20)$ are not shown since the majority of tumours were reported to be unmethylated regardless of the level of MGMT immunoexpression.

All data were entered anonymously into a Microsoft Excel 2011 computer database centrally. Analysis was performed using STATA, version 14.0 (STATA Corp.).

\section{Results}

\section{Patient cohort and tumour characteristics}

A total of 166 patients were included in the study cohort, with case submission from 67 contributors across 17 European countries, Argentina, Australia, Brazil, Columbia, Japan and USA. Treatment was given between 2006 and 2016. Tumours with metastases were classified as PC $(n=40)$ and without metastases as APT $(n=125$, Table 1$)$. For one patient, the diagnosis was not provided. The APTs were characterised by invasive growth in $109 / 125$ (87\%), tumour growth after radiotherapy in $87 / 125$ (70\%), tumour growth following 2 prior surgeries in $86 / 125(69 \%)$ and resistance to medical therapy in $68 / 125$ (54\%). Mean age at diagnosis of the pituitary tumour was 43 years (range: 4-79 years), 64\% were men. Patients underwent a mean of 2.7 pituitary surgeries and 1.2 courses of radiotherapy. The majority of the tumours (69\%) were clinically functioning at the time of data collection (Table 1 for immunohistochemical subtypes). Out of 68 clinically silent tumours at the time of diagnosis, $17(25 \%)$ subsequently became functional.

\section{Markers of proliferation, p53 and MGMT}

At the last surgery, $82 \%(109 / 131)$ tumours showed a Ki-67 index $\geq 3 \%$ with no clear difference between
APT and PC with a median $7 \%$ and $10 \%$ respectively (Fig. 2 and Table 1). Furthermore, Ki-67 index $\geq 10 \%$ also did not discriminate between APT and PC, even after performing a sensitivity analysis in which two APT patients with very high Ki67 (60\% and 90\%) were excluded. Other markers were reported in fewer patients. In PC, mitotic rates $\geq 2$ per 10 high power fields (HPF) were more prevalent compared with APT, p53 expression did not differ between APT and PC (Table 1). All three markers were examined in 39 patients only and were more often positive in patients with PC compared with APT, $P=0.08$ (Table 2). MGMT immunohistochemistry was examined in 65 tumours. Low MGMT expression was seen in $63 \%$, intermediate in $11 \%$ and high in $26 \%$, with no difference between APT and PC (Table 1). Immunonegative tumours (no hormonal content) had a higher proportion of high MGMT expression (5/8, 63\%) compared with immunopositive tumours $(12 / 57,21 \%)$, $P=0.02$ (Table 1).

\section{First-line treatments of aggressive pituitary tumours/carcinomas}

TMZ was chosen as first-line chemotherapy in 157 cases, 116/125 APT, all 40 PC and the patient with unclassified tumour extension. An additional 7 patients with APT received other cytotoxic or biological therapies as first line with variable outcomes (3 PR, 4 PD). First-line treatment with peptide receptor radionuclide therapy (PRRT) was used in 2 APT of which 1 had a PR and the other SD.

\section{Temozolomide as first-line}

treatment - treatment schedules

Most frequently (139/150, 93\%), the standard dosing regimen $\left(150-200 \mathrm{mg} / \mathrm{m}^{2}\right.$ for 5 days in 28 day cycles) was used as monotherapy. In 6 patients, the 'Stupp' protocol was employed, $75 \mathrm{mg} / \mathrm{m}^{2} \mathrm{TMZ}$ daily for 6 weeks during radiotherapy followed by 6-12 months of standard dosing (15). Other dosing variations included continuous daily dosing with $50 \mathrm{mg} / \mathrm{m}^{2}(n=2)$ and a dose-dense regime comprising 21 days of $140 \mathrm{mg} / \mathrm{m}^{2}$ daily followed by 7 days off in a 28-day cycle $(n=1) .136$ patients received TMZ for a median of 9 months (range 1-36). Treatment duration was pre-prescribed by the treating team in 68 patients, other reasons for cessation of TMZ were tumour progression or lack of regression $(n=53)$ and side effects $(n=16)$.

TMZ was used concomitantly with radiotherapy in 14 patients (10 APT, 4 PC). In 6 patients, an additional 
Table 1 Baseline characteristics stratified by diagnosis. Data are presented as $n(\%)$

\begin{tabular}{|c|c|c|c|}
\hline & Aggressive pituitary tumour & Pituitary carcinoma & P-Value \\
\hline Total $(n)$ & 125 & 40 & \\
\hline Age at diagnosis, mean (s.D.) & $42.7(16.2)$ & $44.7(15.1)$ & 0.51 \\
\hline Gender $(n=164)$ & & & 0.82 \\
\hline Female $(n=59)$ & $44(35.5 \%)$ & $15(37.5 \%)$ & \\
\hline Male $(n=105)$ & $80(64.5 \%)$ & $25(62.5 \%)$ & \\
\hline Clinical subtype $(n=165)$ & & & 0.018 \\
\hline Clinically functioning $(n=97)$ & $72(57.6 \%)$ & $25(62.5 \%)$ & \\
\hline Initially silent becoming functional $(n=17)$ & $9(7.2 \%)$ & $8(20.0 \%)$ & \\
\hline Clinically non-functioning $(n=51)$ & $44(35.2 \%)$ & $7(17.5 \%)$ & \\
\hline Pathological subtype(s) at last surgery $(n=165)$ & & & 0.14 \\
\hline Corticotroph $(n=75)$ & $56(44.8 \%)$ & $19(47.5 \%)$ & \\
\hline Gonadotroph $(n=6)$ & $5(4.0 \%)$ & $1(2.5 \%)$ & \\
\hline Somatotroph $(n=16)$ & $14(11.2 \%)$ & $2(5.0 \%)$ & \\
\hline Immunonegative $(n=24)$ & $21(16.8 \%)$ & $3(7.5 \%)$ & \\
\hline Lactotroph $(n=40)$ & $25(20.0 \%)$ & $15(37.5 \%)$ & \\
\hline Thyreotroph $(n=4)$ & $4(3.2 \%)$ & $0(0.0 \%)$ & \\
\hline $\mathrm{Ki}-67(n=131)$ & & & 0.84 \\
\hline$<3 \%(n=23)$ & $18(19 \%)$ & $5(15 \%)$ & \\
\hline$\geq 3 \%(n=62)$ & $46(47 \%)$ & $16(47 \%)$ & \\
\hline$\geq 10 \%(n=46)$ & $33(34 \%)$ & $13(38 \%)$ & \\
\hline Mitotic count $(n=61)$ & & & 0.030 \\
\hline$<2 / 10 \mathrm{HPF}(n=17)$ & $15(37 \%)$ & $2(10 \%)$ & \\
\hline$>2 / 10 \mathrm{HPF}(n=44)$ & $26(63 \%)$ & $18(90 \%)$ & \\
\hline p53 immunodetection $(n=71)$ & & & 0.63 \\
\hline Negative $(n=18)$ & $13(27 \%)$ & $5(22 \%)$ & \\
\hline Positive $(n=53)$ & $35(73 \%)$ & $18(78 \%)$ & \\
\hline MGMT $(n=65)$ & & & 0.96 \\
\hline IHC low $(n=41)$ & $30(63 \%)$ & $11(65 \%)$ & \\
\hline IHC int $(n=7)$ & $5(10 \%)$ & $2(12 \%)$ & \\
\hline IHC high $(n=17)$ & $13(27 \%)$ & $4(24 \%)$ & \\
\hline Number of surgeries $(n=147)$ & & & 0.81 \\
\hline $0(n=5)$ & $4(3.6 \%)$ & $1(2.8 \%)$ & \\
\hline $1(n=27)$ & $21(18.9 \%)$ & $6(16.7 \%)$ & \\
\hline 2 or $3(n=73)$ & $55(49.5 \%)$ & $18(50.0 \%)$ & \\
\hline$\geq 4(n=42)$ & $31(27.9 \%)$ & $11(30.5 \%)$ & \\
\hline Number of radiotherapy courses $(n=147)$ & & & 0.014 \\
\hline $0(n=13)$ & $12(10.7 \%)$ & $1(2.9 \%)$ & \\
\hline $1(n=90)$ & $71(63.4 \%)$ & $19(54.3 \%)$ & \\
\hline $2(n=41)$ & $29(25.9 \%)$ & $12(34.3 \%)$ & \\
\hline 3 or $4(n=3)$ & $0(0.0 \%)$ & $3(8.6 \%)$ & \\
\hline
\end{tabular}

chemotherapeutic agent was used in combination with first-line TMZ: capecitabine (3), bevacizumab (1), thalidomide and BCNU (1 each).

\section{Response to first-line temozolomide treatment}

Biochemical response was recorded as complete in 19\% (21/113), partial in 34\% (38/113), stable in 27\% (30/113) and progression in $21 \%(24 / 113)$. Of those with partial biochemical regression, 53\% (20/38) had more than $75 \%$ reduction in hormone levels. The overall radiological response rate to TMZ was 37\% (Table 3). Length of TMZ therapy was longer in responders (median 12 months) compared to progressors (median 5.5 months). In the
59 patients who achieved a biochemical response (>20\% decrease in hormone levels), a radiological response (>30\% tumour regression) was obtained in 73\%. Time to maximal radiological response was reported in 39 patients and occurred within the first 3 cycles in 23\% and by month 6 in 59\% patients. Among those with PR, 52\% had $>50 \%$ tumour size reduction. Clinically functioning tumours were more likely to demonstrate regression on TMZ compared with non-functioning tumours (45\% vs $17 \%, P=0.01$, Fig. 3), an effect that was independent of the MGMT status (odds ratio 3.35, 95\% CI 1.03-10.9). There was no clear difference in efficacy between men and women, among functioning tumour subtypes or between APT and PC. 


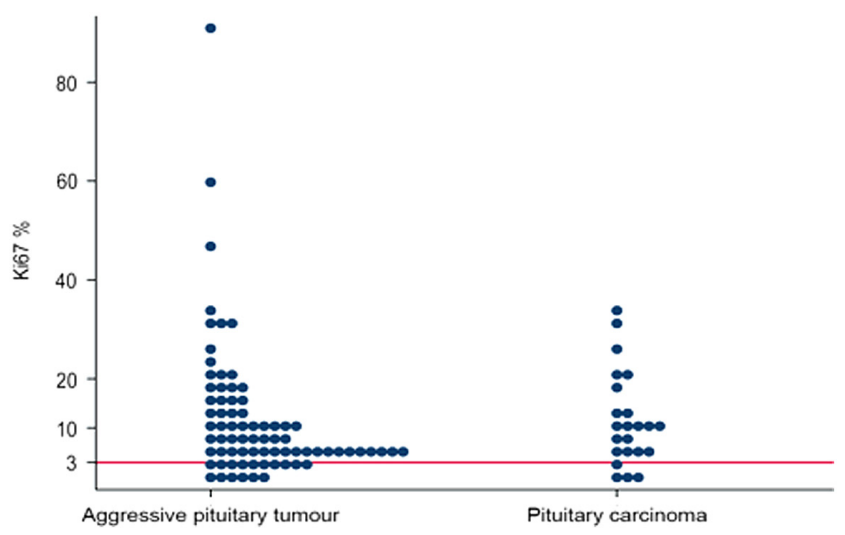

Figure 2

Ki-67 index determined in 76 patients with APT and 23 with PC.

Response to temozolomide in combination with radiotherapy or other cytotoxic drugs

Concomitant radiotherapy and TMZ given to 14 patients was associated with an increased response rate compared to TMZ monotherapy ( $P=0.02$; Fig. 4$)$. A CR or PR was seen in $71 \%$ compared with $34 \%$ of those receiving TMZ monotherapy. The two treatment groups did not differ clearly with respect to age, the proportion of patients with PC and tumour subtypes.

Two of the 6 cases treated with TMZ in combination with another chemotherapeutic agent achieved a PR (1 case with bevacizumab and 1 with capecitabine). Stable disease was seen in another case using capecitabine and another with thalidomide, while PD was seen in two cases with BCNU and capecitabine, respectively.

\section{Tumour histopathological characteristics and the response to temozolomide}

Tumours with low MGMT expression often achieved regression during TMZ treatment, 19/41 (46\%), whereas

Table 2 Expression of all 3 markers of aggressiveness (Ki-67 index, mitotic count and p53 expression) in 39 pituitary aggressive tumours and carcinomas.

\begin{tabular}{lccc}
\hline $\begin{array}{l}\text { No. of positive } \\
\text { markers* }\end{array}$ & Aggressive tumours & Carcinomas \\
\cline { 1 - 2 } $\begin{array}{lcc}n \\
1\end{array}$ & 4 & 0 \\
2 & 9 & 3 \\
3 & 12 & 10 \\
Total & 26 & 13 \\
\hline
\end{tabular}

*A positive marker was defined as $\mathrm{Ki} 67 \geq 3 \%$ or p53 positivity or mitotic rate $>2 / 10$ HPF. tumours with high MGMT expression more often showed no response (13/17, 76\%) (Fig. 5). A complete response (CR) was only seen among tumours with low MGMT expression. Progression was more frequent in tumours with Ki-67 index $\geq 10 \%$ vs $<10 \%$ (18/44 (41\%) vs $12 / 51$ (24\%), $P=0.023)$. Response rates were not different between p53-positive or -negative tumours (Table 3). Effect modification by mitotic count could not be determined due to few data.

\section{Side effects}

Clinically relevant side effects from TMZ treatment were reported in 33/157 patients, the most common being development of cytopaenias ( $n=14$; thrombocytopaenia $n=7$, leukopenia $n=2$ or combination $n=5)$, fatigue $(n=11)$ and nausea/vomiting $(n=10)$. One patient developed sensorineural hearing loss. In 3 of 4 cases treated with etoposide serious side effects were reported (cytopaenias, hyperemesis). No side effects were reported in the 7 patients treated with PRRT.

\section{Tumour status after temozolomide cessation}

At the close of case submissions, 12 patients were still receiving TMZ treatment. Of 148 patients who had completed a first course of TMZ, the median follow-up was 21 months (range 0-102 months) after drug cessation, similar for PC (18 months) and APT (22 months). Tumour progression was common after TMZ cessation among the patients who had CR, PR or SD while on TMZ (Fig. 6). In total, progression occurred in 38 while a treatment effect was sustained in 52 patients. The median time to progression after TMZ cessation was 12 (range 1-60) months with no difference among those with PR or SD. In 2 of 9 patients with CR, progression was detected in 2 carcinomas after 48 and 60 months.

\section{Second-line treatments - outcome}

Of the 48 patients in whom PD was seen while receiving TMZ, 24 subsequently received alternative second- or third-line therapies with other drugs. Two of these achieved PR (Table 4). A second course of TMZ given in 4 patients (in 3 combined with either capecitabine $(n=1)$ or bevacizumab $(n=2)$ ) resulted in further progress in 3 , the outcome on one is still awaited. Twenty patients received no further treatment.

Of the 38 patients who progressed after cessation of a first course of TMZ, 24 received a second course of 
Table 3 Effect of treatment with temozolomide. Data are presented as $n(\%)$.

\begin{tabular}{|c|c|c|c|c|c|}
\hline & Complete regression & Partial regression & Stable disease & Progression & P-Value \\
\hline Total & $9(6 \%)$ & $49(31 \%)$ & $52(33 \%)$ & $47(30 \%)$ & \\
\hline Patient gender & & & & & 0.20 \\
\hline Female $(n=55)$ & $6(11 \%)$ & $16(29 \%)$ & $19(35 \%)$ & $14(25 \%)$ & \\
\hline Male $(n=101)$ & $3(3 \%)$ & $32(32 \%)$ & $33(33 \%)$ & $33(33 \%)$ & \\
\hline Diagnosis & & & & & 0.051 \\
\hline Aggressive pituitary tumour $(n=116)$ & $5(4 \%)$ & $36(31 \%)$ & $45(39 \%)$ & $30(26 \%)$ & \\
\hline Pituitary carcinoma $(n=40)$ & $4(10 \%)$ & $13(33 \%)$ & $7(18 \%)$ & $16(40 \%)$ & \\
\hline What was the clinical subtype? & & & & & 0.011 \\
\hline Clinically functioning $(n=94)$ & $6(6 \%)$ & $37(39 \%)$ & $27(29 \%)$ & $24(26 \%)$ & \\
\hline Initially silent becoming functioning $(n=16)$ & $2(13 \%)$ & $5(31 \%)$ & $2(13 \%)$ & $7(44 \%)$ & \\
\hline Clinically non-functioning $(n=47)$ & $1(2 \%)$ & $7(15 \%)$ & $23(49 \%)$ & $16(34 \%)$ & \\
\hline Pathological subtype(s) at last surgery & & & & & 0.27 \\
\hline Corticotroph $(n=73)$ & $6(8 \%)$ & $22(30 \%)$ & $20(27 \%)$ & $25(34 \%)$ & \\
\hline Gonadotroph $(n=6)$ & $0(0 \%)$ & $1(17 \%)$ & $4(67 \%)$ & $1(17 \%)$ & \\
\hline Somatotroph $(n=14)$ & $1(7 \%)$ & $5(36 \%)$ & $4(29 \%)$ & $4(29 \%)$ & \\
\hline Immunonegative $(n=22)$ & $0(0 \%)$ & $3(14 \%)$ & $11(50 \%)$ & $8(36 \%)$ & \\
\hline Lactotroph $(n=38)$ & $2(5 \%)$ & $17(45 \%)$ & $10(26 \%)$ & $9(24 \%)$ & \\
\hline Thyrotroph $(n=4)$ & $0(0 \%)$ & $1(25 \%)$ & $3(75 \%)$ & $0(0 \%)$ & \\
\hline Ki-67 index & & & & & 0.17 \\
\hline$<3 \%(n=23)$ & $1(4 \%)$ & $5(22 \%)$ & $10(44 \%)$ & $7(30 \%)$ & \\
\hline$\geq 3 \%(n=58)$ & $5(9 \%)$ & $17(29 \%)$ & $21(36 \%)$ & $15(26 \%)$ & \\
\hline$\geq 10 \%(n=44)$ & $2(5 \%)$ & $17(39 \%)$ & $7(16 \%)$ & $18(41 \%)$ & \\
\hline p53 immunodetection & & & & & 0.39 \\
\hline Negative $(n=18)$ & $2(11 \%)$ & $6(33 \%)$ & $6(33 \%)$ & $4(22 \%)$ & \\
\hline Positive $(n=53)$ & $2(4 \%)$ & $14(26 \%)$ & $15(28 \%)$ & $22(42 \%)$ & \\
\hline MGMT immunohistochemistical expression & & & & & 0.31 \\
\hline $\operatorname{Low}(n=41)$ & $6(15 \%)$ & $13(32 \%)$ & $15(37 \%)$ & $7(17 \%)$ & \\
\hline Intermediate $(n=7)$ & $0(0 \%)$ & $3(43 \%)$ & $2(29 \%)$ & $2(29 \%)$ & \\
\hline High $(n=17)$ & $0(0 \%)$ & $4(24 \%)$ & $\begin{array}{r}6(35 \%) \\
15(37 \%)\end{array}$ & $7(41 \%)$ & \\
\hline
\end{tabular}

TMZ. Six progressors received alternative second- or thirdline therapies (Table 4), and in 8 patients, no further treatment was given. In 18 patients, the outcome of a second course of TMZ was reported. Two achieved PR (1 on monotherapy, 1 on TMZ+bevacizumab), 5 had SD (however in 3 additional treatment was also given) and 11 had PD.

Radiotherapy given in 10 patients as a second- or third-line treatment, either in an attempt to prevent tumour progression after TMZ cessation $(n=8)$ or to arrest progressively growing tumours during a second course of TMZ $(n=2)$, had limited effects (Table 4$)$.

Of the seven patients in whom alternative first-line chemotherapy was given, three went on to receive secondline therapy with TMZ using a standard dosing regime. Two patients had PR and SD, respectively, but progressed following TMZ cessation. The third patient had PD while on TMZ.

PRRT was administered as second- or third-line treatment in 5 patients, but all continued to demonstrate tumour progression. In addition, pasireotide was given in 5 patients with corticotroph tumours with no effect.

\section{Mortality}

Reflecting the aggressive nature of the tumours in this cohort, $28 \%$ of patients with APT and $42.5 \%$ of PC were reported deceased. The median duration from initial diagnosis of pituitary tumour to death was 11 years across

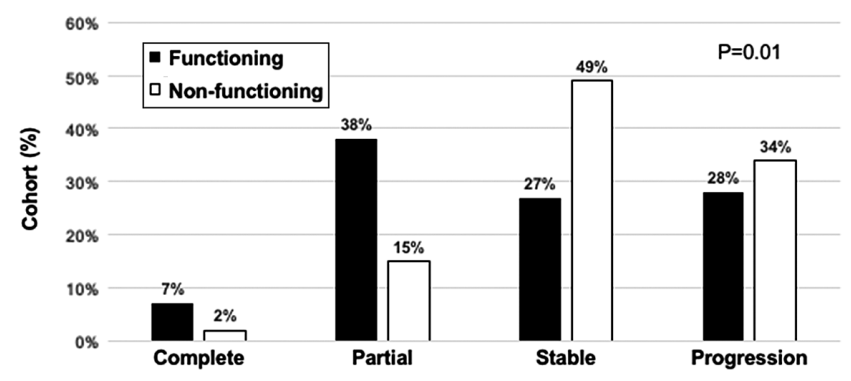

Figure 3

Radiological response to $\mathrm{TMZ}$ in 157 tumours divided into clinically functioning $(n=110)$ and non-functioning $(n=47)$. Response defined as complete $=$ no visible tumour; partial response $=30-99 \%$ regression, stable $<30 \%$ regression and $<10 \%$ progression, progression $=>10 \%$ progression . 


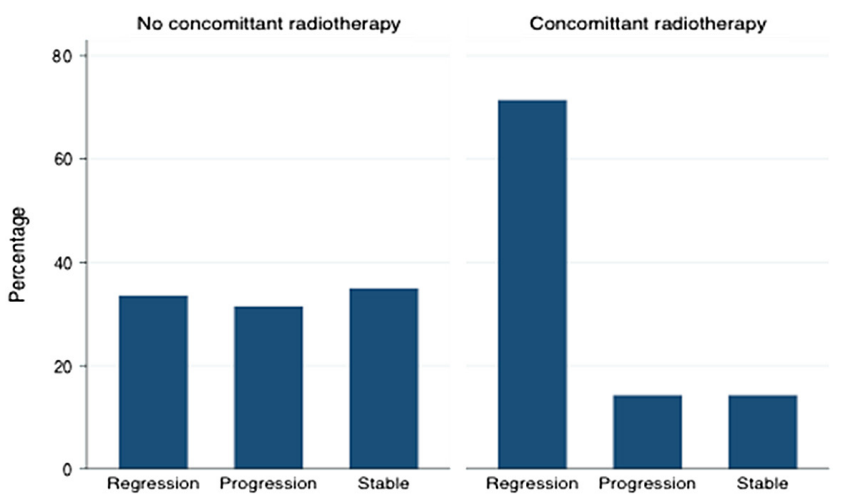

Figure 4

Concomitant radiotherapy and TMZ are associated with an increased response rate compared to $T M Z$ alone. $R T+T M Z$ was given in 14 patients, TMZ alone 131 patients.

the cohort (range 1-31), 11 and 12 years respectively among APT and PC. The highest mortality was seen among patients who progressed while receiving TMZ $(26 / 47,55 \%)$ with no deaths in those patients who had a CR to TMZ.

\section{Discussion}

The present survey reports the largest cohort of patients with APT and carcinomas, including 100 previously unpublished cases. With data collected from 21 countries these results represent the current management of these rare and challenging tumours in clinical practice.

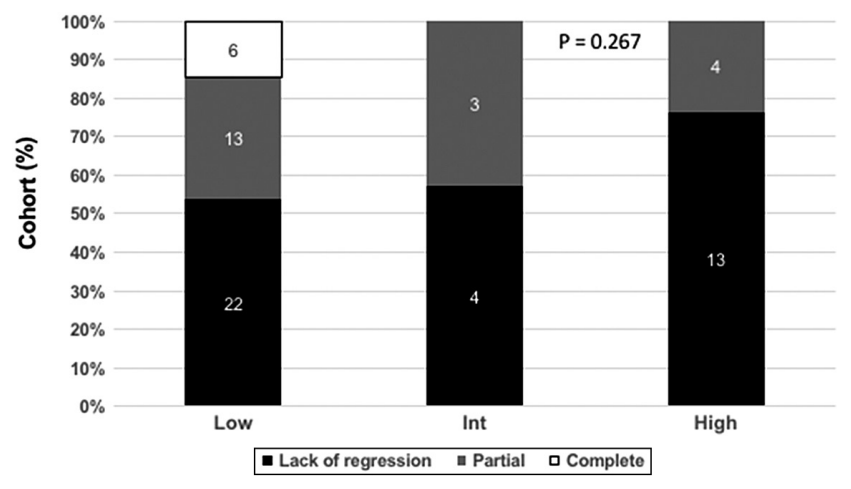

Figure 5

Low MGMT expression is more frequently associated with response to TMZ. Results from 65 tumours examined for MGMT by immunohistochemistry. MGMT expression (low $<10 \%$ positive cell, intermediate $10-50 \%$ positive cells, high $>50 \%$ positive cells) and response to TMZ (lack of regression black, partial regression grey, complete regression white).

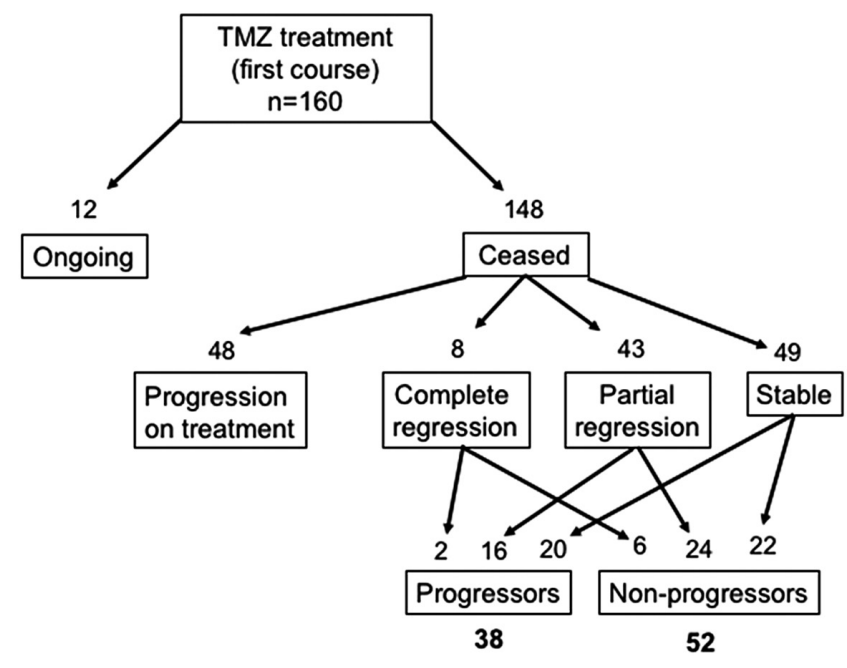

Figure 6

Tumour progression after TMZ cessation.

Almost all patients, 95\%, had received TMZ as first-line chemotherapy when standard treatment regimens had failed. Tumour regression occurred in 58/157 (37\%), confirming the response rate reported in previous smaller series $(2,13,19,24)$. Early assessment of treatment is important given that maximal radiological response occurred within 6 months in $60 \%$ of patients. Stable disease was reported in a significant number of patients (33\%) in whom 60\% continued treatment beyond 6 months. Depending on the pretreatment growth rate, stable disease may represent a positive outcome of TMZ therapy.

Nine patients (6\%) had complete regression, an effect achieved both in aggressive APT and PC. A comparable response has not been reported with conventional cytotoxic drugs, which, at the most, have produced a partial, and usually transient, tumour regression (10). CR was only seen in patients with low MGMT expression, whereas no tumour regression was seen in 13/17 patients with high MGMT. MGMT status by methylation PCR was assessed in only a few cases, but as has been shown previously for pituitary tumours, there was a poor correlation between methylation result and immunohistochemical expression $(24,25,26,27)$. Low MGMT has been shown to predict the response to TMZ in malignant gliomas (28) as well as in some neuroendocrine tumours (29). In APTs, the predictive value has been debated. Methodological problems including absence of an internal positive control (vascular endothelial cells), lack of uniform cut-off levels for defining low, intermediate and high staining patterns, inter-observer variations (25), as well as differing response 
Table 4 Alternate oncological treatment (non-TMZ drugs and radiotherapy) as second- and third-line treatments.

\begin{tabular}{|c|c|c|c|}
\hline Agent & $\begin{array}{l}\text { Number } \\
\text { of cases }\end{array}$ & Stable & Progression \\
\hline Cisplatin + etoposide & 2 & & 2 \\
\hline Carboplatin + etoposide & 3 & & 3 \\
\hline Bevacizumab & 3 & 1 & 1 \\
\hline Cisplatin + adriblastin & 1 & 1 & \\
\hline Capecitabine & 1 & & 1 \\
\hline Cisplatin + capecitabine & 1 & & \\
\hline Cisplatin + 5FU & 1 & & 1 \\
\hline Doxorubicin + 5FU & 1 & & 1 \\
\hline Oxaliplatin + 5FU & 1 & & 1 \\
\hline Etoposide & 2 & & 2 \\
\hline $\begin{array}{l}\text { Etoposide }+ \\
\text { cyclophosphamide }\end{array}$ & 1 & & 1 \\
\hline Everolimus & 3 & & 3 \\
\hline Erlotinib & 1 & & 1 \\
\hline Lapatinib & 2 & & 2 \\
\hline Sunitib & 1 & & 1 \\
\hline Radiotherapy & 10 & 4 & 6 \\
\hline
\end{tabular}

criteria, all likely contribute to the reported discrepancies. All these limitations most be considered when interpreting the data in the present survey. In a series of patients where all specimens were investigated by a single pathologist and the criteria for tumour regression uniform, low MGMT expression was found to predict a good effect of TMZ (2). Besides the problems mentioned earlier, tumour heterogeneity not recognised in small specimens may complicate the picture, since parts of the pituitary tumour with low MGMT content may respond, leading to an initial regression of tumour mass (2). However, factors other than MGMT may modulate the effect of TMZ. Data on MSH6 immunohistochemistry was not available in this cohort but has been described to influence response to TMZ in a limited number of cases $(19,30)$ but not in other studies $(2,20)$. A novel finding in this survey was that functioning tumours responded better than nonfunctioning tumours, an observation that was not related to MGMT status. As a group functional tumours tended to have higher Ki-67 indices, but markers of proliferation and p53 did not influence the outcome.

$\mathrm{TMZ}$ is considered to be a radiosensitiser based on data from vitro studies $(31,32)$. Fourteen patients in the present study had received TMZ and radiotherapy (RT) concurrently, 6 in accordance with the standard regime in glioblastoma (15). In this group, 71\% achieved tumour regression vs 34\% (45/131) in the larger group treated with TMZ monotherapy. There were no clear clinical or pathological differences between the two groups. In the majority of patients in the $\mathrm{TMZ}+\mathrm{RT}$ group, their initial course of radiotherapy was delivered with TMZ; however, room for additional radiation was considered in 2 cases. Prolonged tumour control following combination TMZ and radiotherapy in APT has also been suggested by others $(13,33)$; however, it should be pointed out that no studies have compared TMZ monotherapy to TMZ+RT in a randomised design.

Six patients in the survey had received TMZ in combination with other cytotoxic drugs including capecitabine in three cases. While 2 cases receiving firstline combination treatment with TMZ (1 bevacizumab, the other capecitabine) reported partial regression, it is possible these cases would have responded to TMZ alone. Given the small numbers treated, no firm conclusions can be drawn about upfront combination therapy with TMZ. In a previous report on a successful outcome of $\mathrm{TMX}+$ capecitabine in four aggressive corticotroph tumours, the two drugs were given sequentially starting with capecitabine, which theoretically could be an advantage (20). In other studies, addition of capecitabine in TMZ failures did not alter the clinical course, similar to the present data $(2,13)$.

One of the most difficult clinical dilemmas is when to discontinue $\mathrm{TMZ}$ in responding patients. In this survey, the median treatment duration was 9 months; this reflects that in close to $50 \%$ of patients, the treatment period was pre-determined as 6 or 12 months, based on general oncological practice with TMZ in patients with glioblastoma multiforme. Twenty-one patients received 18-36 months of TMZ therapy. Longer treatment duration was associated with a higher response rate; however, it seems likely that physicians would continue treatment for a longer time in responding patients. Thus, a true effect on length of therapy and response rate could not be determined in this observational study. TMZ was generally well tolerated, $11 \%$ of patients discontinued due to adverse events, most frequently bone marrow suppression, especially leukopenia and/or thrombocytopenia. One case of sensorineural hearing loss was described, this complication has been reported in another pituitary patient and among non-pituitary tumours $(25,34)$. Alternative $\mathrm{TMZ}$ dosing regimens were described in only 3 cases. One patient receiving a dose-dense regime for 12 months had partial tumour regression while the 2 on continuous lowdose daily administration exhibited stable disease after 12-15 months of TMZ. In patients with glioblastomas, dose-dense protocols have been accompanied by more side effects, especially pronounced leukopenia, but not a higher response rate (35).

The high proportion of patients demonstrating tumour progression after TMZ cessation, in combination 
with a poor response to alternative treatments, may support continuing treatment with TMZ beyond the commonly used 6-12 months, especially in patients with few side effects. In 18 of 51 (35\%) patients, who initially responded to $\mathrm{TMZ}$, and 20 of 49 (41\%) with stable disease on treatment, subsequent tumour progression was documented during a median follow-up of 21 months across the cohort. Eighteen of these cases received a second course of TMZ, but a subsequent partial regression was seen in only two (11\%), one of whom was treated with TMZ in combination with bevacizumab, a monoclonal antibody directed against the vascular endothelial growth factor-A (VEGF-A). This is in line with a poor response of TMZ given a second time in other studies $(2,13)$. Possibly, initially TMZ-sensitive tumour clones had been ameliorated, leaving drug-resistant clones to develop, reflecting the innate biology of many aggressive tumours. Other drugs given as second- or third-line treatments in a total of 30 patients led to partial tumour regression in 2 cases, and radiotherapy in this setting had limited effects.

Data on 12 patients with PRRT and specific follow-up data available have been reported in the literature: $4 \times{ }^{111}$ Indium $(36,37), 5 \times{ }^{177}$ Lutetium $(2,38,39)$ and $4 \times{ }^{90} \mathrm{Y}(2,40)$, with tumour regression in 4 and stable disease for 8 years in 1 patient. Therapy was limited to patients with prior demonstration of marked uptake in tumour tissue by either octreoscan or 68Ga-DOTATOCPET, and therefore, presents a highly selected patient group. The survey contained 7 patients, with PR in 1 and SD in 1, both of whom received PRRT as first-line treatment. The other 5 received PRRT as second- or thirdline treatment after progression on TMZ. To what extent APTs express somatostatin receptors sufficient for PRRT is not known, and the precise value of PRRT in the treatment algorithm of these tumours remains unclear.

In the present study cohort, $82 \%$ of the tumours have a Ki-67 index $\geq 3 \%$. Proliferative markers (Ki-67 index, mitotic count) and p53 expression did not differentiate APT from PC. Although PC as a group were more likely to have three markers indicative of aggressive behaviour (Ki$67 \geq 3 \%$, >2 mitotic counts/10 HFF, p53 positivity), there was a considerable overlap between the two groups. In line with previous studies with APT and PC, there was an overrepresentation of corticotroph tumours, $45 \%$ in our cohort, compared with less than 6-10\% among pituitary tumours as a whole in clinical or pathological series (4, 41). Another finding of clinical relevance was the high proportion of initially silent corticotroph or somatotroph tumours that evolved into clinically functioning
ACTH- and GH-secreting tumour, respectively, occurring in $26 \%$ of the silent tumours. It is known that silent corticotroph adenomas may evolve into aggressive tumours or carcinomas $(42,43)$. Others have reported a shift in the secreted hormone, from prolactin only to both prolactin and $\mathrm{GH}(2,44)$, from a silent to a prolactin and TSH-secreting tumour (45) in parallel with tumour enlargement and/or transformation into a carcinoma. Whether this phenomenon represents a gain of secretory function or merely is an effect of an enlarging tumour and thereby higher amounts of hormones initially secreted at levels below the limit of detection remains to be investigated. A report of an aggressive lactotroph tumour evolving into a somatotroph tumour coincident with a GNAS gene mutation would support the first alternative (46). Taken together, although no single parameter reliably could predict metastatic disease, the presence of high mitotic numbers, ACTH secretion and a switch in phenotype from clinically silent to hormone secreting, should alert the physician of a potentially more aggressive course.

The data of the present paper were based on a survey among treating physicians of patients with APT or PC. Some limitations should be taken into account in the interpretation of the data. Firstly, the retrospective nature of the data collected can introduce bias in clinician reporting. Secondly, the exact date of an event (tumour progression, death) was often not well recorded, which hampers formal time-to-event analysis. In line, 'stable disease' depends ultimately on follow-up time and as this was often not specified, the interpretation of stable is difficult. Thirdly, some examinations (for example, pathology markers) were only performed in a subset of patients and may not have been reported by an expert pituitary pathologist, which means that the generalizability of the findings to the whole cohort cannot be automatically assumed. Finally, the follow-up protocol (timing and frequency of MR scanning) might have differed between patients.

In summary, this international, cross-sectional study has confirmed TMZ as an effective drug in the treatment of APT and PC and represents the largest series of such tumours reported. Novel findings were the better response rate in functioning tumours and a better response when TMZ was given concurrently with radiotherapy. The latter needs to be validated in future studies. Tumour MGMT status remains a potential marker of response to TMZ. Markers of proliferation were not useful predicting response to $\mathrm{TMZ}$ and also did not differentiate APTs 
from PCs. Of major importance, our results illustrate the significant tumour progression rate occurring following TMZ cessation and high mortality rates in this group of patients. The question of the ideal length of therapy with TMZ remains open for future exploration. The poor outcome of a second course of TMZ in relapsing tumours as well as in tumours initially progressing on TMZ underscores the need for finding effective alternative therapies. A European registry on these rare tumours could provide more insights into their clinical and pathological characteristics and enable the identification of new treatment regimens.

\section{Declaration of interest}

The authors declare that there is no conflict of interest that could be perceived as prejudicing the impartiality of this study.

Funding

This study was supported by the European Society of Endocrinology.

\section{Acknowledgements}

Alex Harrison, ESE Program Development Manager, for his important role in conducting this study.

ESE survey collaborators: Alicia Hubalewska-Dydejezky, Guillaume Assie, Leon Bach, Marie Batisse-Lignier, Katarina Berinder, Ismene Bilbao, Fabrice Bonnet, Damien Bresson, Oscar Bruno, Mariana Campdera, Philippe Caron, Frederic Castinetti, Filippo Ceccato, Olivier Chabre, Philippe Chanson, Emanuel Christ, Lucie Cloix, Christine Cortet, Lise Criniere, Guillem Cuatrecasas, Miguel Debono, Brigitte Delemer, Rachel Desailloud, Timo Deutschbein, Tina Dusek, Britt Eden Engström, Marco Faustini-Fustini, Schillo Franck, Cyril Garcia, Yona Greenman, Susana Mallea Gil, Giovanna Mantovani, Mark Gurnell, Anthony Heaney, David Henley, Claire Higham, EW Hoving, Charlotte Höybye, Atsuhiro Ichihara, Marie-Lise Jaffrain-Rea, Gudmundur Johannsson, Jens Otto Lunde Jorgensen, Christel Jublanc, Jan Komor, Marta Korbonits, Ivana Kralievic, Delphine Larrieu-Ciron, Helene Lasolle, Edward Laws, Marco Losa, Dominique Maiter, Claudio Marcocci, Olinda Castro Marques, Tania Longo Mazzuco, Alexander Micko, Nathalie Bourcigaux, Sebastian Neggers, John Newell-Price, Belén Perez-Berida, Leon D Ortiz, Oskar Ragnarsson, Marta Ragonese, Martin Reincke, Jean-Louis Sadoul, Akira Shimatsu, Luis V Syro, Luc Taillandier, Miklos Toth, Takeshi Usui, Zauzsanna Valkusz, Greisa Vila, Ben Whitelaw, Maria Chiara Zatelli.

\section{References}

1 Heaney AP. Clinical review: pituitary carcinoma: difficult diagnosis and treatment. Journal of Clinical Endocrinology and Metabolism 2011 96 3649-3660. (https://doi.org/10.1210/jc.2011-2031)

2 Bengtsson D, Schroder HD, Andersen M, Maiter D, Berinder K, Feldt Rasmussen U, Rasmussen AK, Johannsson G, Hoybye C, van der Lely AJ et al. Long-term outcome and MGMT as a predictive marker in 24 patients with atypical pituitary adenomas and pituitary carcinomas given treatment with temozolomide. Journal of Clinical Endocrinology and Metabolism 2015100 1689-1698. (https://doi. org/10.1210/jc.2014-4350)

3 Raverot G, Burman P, McCormack AI, Heaney AP, Petersenn S, Popovic V, Trouillas J \& Dekkers O. European Society of Endocrinology clinical practice guidelines for the management of aggressive pituitary tumours and carcinomas. European Journal of Endocrinology $2017 \mathbf{1 7 8}$ G1-G24. (https://doi.org/10.1530/EJE-17-0796)

4 DeLellis RA, Lloyd RV, Heitz PU \& Eng C. Pathology and genetics of tumours of endocrine organs. In World Health Organization Classification of Tumours. Lyon: IARC Press, 2004.

5 Saeger W, Ludecke DK, Buchfelder M, Fahlbusch R, Quabbe HJ \& Petersenn S. Pathohistological classification of pituitary tumors: 10 years of experience with the German Pituitary Tumor Registry. European Journal of Endocrinology 2007156 203-216. (https://doi. org/10.1530/eje.1.02326)

6 Di Ieva A, Rotondo F, Syro LV, Cusimano MD \& Kovacs K. Aggressive pituitary adenomas - diagnosis and emerging treatments. Nature Reviews Endocrinology 201410 423-435. (https://doi.org/10.1038/ nrendo.2014.64)

7 Lopes MBS. The 2017 World Health Organization classification of tumors of the pituitary gland: a summary. Acta Neuropathologica 2017 134 521-535. (https://doi.org/10.1007/s00401-017-1769-8)

8 Trouillas J, Roy P, Sturm N, Dantony E, Cortet-Rudelli C, Viennet G, Bonneville JF, Assaker R, Auger C, Brue T et al. A new prognostic clinicopathological classification of pituitary adenomas: a multicentric case-control study of 410 patients with 8 years postoperative follow-up. Acta Neuropathologica 2013126 123-135. (https://doi.org/10.1007/s00401-013-1084-y)

9 Raverot G, Dantony E, Beauvy J, Vasiljevic A, Mikolasek S, BorsonChazot F, Jouanneau E, Roy P \& Trouillas J. Risk of recurrence in pituitary neuroendocrine tumors: a prospective study using a fivetiered classification. Journal of Clinical Endocrinology and Metabolism 2017102 3368-3374. (https://doi.org/10.1210/jc.2017-00773)

10 Pernicone PJ, Scheithauer BW, Sebo TJ, Kovacs KT, Horvath E, Young WF Jr, Lloyd RV, Davis DH, Guthrie BL \& Schoene WC. Pituitary carcinoma: a clinicopathologic study of 15 cases. Cancer 199779 804-812. (https://doi.org/10.1002/(SICI)10970142(19970215)79:4<804::AID-CNCR18>3.0.CO;2-3)

11 Ragel BT \& Couldwell WT. Pituitary carcinoma: a review of the literature. Neurosurgical Focus 200416 E7.

12 Kaltsas GA, Mukherjee JJ, Plowman PN, Monson JP, Grossman AB \& Besser GM. The role of cytotoxic chemotherapy in the management of aggressive and malignant pituitary tumors. Journal of Clinical Endocrinology and Metabolism 199883 4233-4238. (https://doi. org/10.1210/jcem.83.12.5300)

13 Losa M, Bogazzi F, Cannavo S, Ceccato F, Curto L, De Marinis L, Iacovazzo D, Lombardi G, Mantovani G, Mazza E et al. Temozolomide therapy in patients with aggressive pituitary adenomas or carcinomas. Journal of Neurooncology 2016126 519-525. (https://doi.org/10.1007/s11060-015-1991-y)

14 Lasolle H, Cortet C, Castinetti F, Cloix L, Caron P, Delemer B, Desailloud R, Jublanc C, Lebrun-Frenay C, Sadoul JL et al. Temozolomide treatment can improve overall survival in aggressive pituitary tumors and pituitary carcinomas. European Journal of Endocrinology 2017176 769-777. (https://doi.org/10.1530/EJE-160979)

15 Stupp R, Mason WP, van den Bent MJ, Weller M, Fisher B, Taphoorn MJ, Belanger K, Brandes AA, Marosi C, Bogdahn U et al. Radiotherapy plus concomitant and adjuvant temozolomide for glioblastoma. New England Journal of Medicine 2005352 987-996. (https://doi.org/10.1056/NEJMoa043330)

16 Lim S, Shahinian H, Maya MM, Yong W \& Heaney AP. Temozolomide: a novel treatment for pituitary carcinoma. Lancet Oncology 20067 518-520. (https://doi.org/10.1016/S14702045(06)70728-8)

17 Fadul CE, Kominsky AL, Meyer LP, Kingman LS, Kinlaw WB, Rhodes CH, Eskey CJ \& Simmons NE. Long-term response of pituitary carcinoma to temozolomide. Report of two cases. Journal of Neurosurgery $2006 \mathbf{1 0 5}$ 621-626. (https://doi.org/10.3171/ jns.2006.105.4.621) 
18 Syro LV, Uribe H, Penagos LC, Ortiz LD, Fadul CE, Horvath E \& Kovacs K. Antitumour effects of temozolomide in a man with a large, invasive prolactin-producing pituitary neoplasm. Clinical Endocrinology 200665 552-553. (https://doi.org/10.1111/j.13652265.2006.02653.x)

19 Hirohata T, Asano K, Ogawa Y, Takano S, Amano K, Isozaki O, Iwai Y, Sakata K, Fukuhara N, Nishioka H et al. DNA mismatch repair protein (MSH6) correlated with the responses of atypical pituitary adenomas and pituitary carcinomas to temozolomide: the national cooperative study by the Japan Society for Hypothalamic and Pituitary Tumors Journal of Clinical Endocrinology and Metabolism 201398 1130-1136. (https://doi.org/10.1210/jc.2012-2924)

20 Zacharia BE, Gulati AP, Bruce JN, Carminucci AS, Wardlaw SL, Siegelin M, Remotti H, Lignelli A \& Fine RL. High response rates and prolonged survival in patients with corticotroph pituitary tumors and refractory Cushing disease from capecitabine and temozolomide (CAPTEM): a case series. Neurosurgery 201474 E447-E455; discussion E455. (https://doi.org/10.1227/NEU.0000000000000251)

21 Zhong C, Yin S, Zhou P \& Jiang S. Pituitary atypical adenoma or carcinoma sensitive to temozolomide combined with radiation therapy: a case report of early identification and management. Turkish Neurosurgery 201424 963-966.

22 Kamiya-Matsuoka C, Cachia D, Waguespack SG, Crane CH, Mahajan A, Brown PD, Nam JY, McCutcheon IE \& Penas-Prado M. Radiotherapy with concurrent temozolomide for the management of extraneural metastases in pituitary carcinoma. Pituitary 201619 415-421. (https://doi.org/10.1007/s11102-016-0721-6)

23 Misir Krpan A, Dusek T, Rakusic Z, Solak M, Kraljevic I, Bisof V, Ozretic D \& Kastelan D. A rapid biochemical and radiological response to the concomitant therapy with temozolomide and radiotherapy in an aggressive ACTH pituitary adenoma. Case Reports in Endocrinology 201720172419590.

24 Raverot G, Sturm N, de Fraipont F, Muller M, Salenave S, Caron P, Chabre O, Chanson P, Cortet-Rudelli C, Assaker R et al. Temozolomide treatment in aggressive pituitary tumors and pituitary carcinomas: a French multicenter experience. Journal of Clinical Endocrinology and Metabolism 201095 4592-4599. (https://doi. org/10.1210/jc.2010-0644)

25 Bush ZM, Longtine JA, Cunningham T, Schiff D, Jane JA Jr, Vance ML, Thorner MO, Laws ER Jr \& Lopes MB. Temozolomide treatment for aggressive pituitary tumors: correlation of clinical outcome with $\mathrm{O}(6)$-methylguanine methyltransferase (MGMT) promoter methylation and expression. Journal of Clinical Endocrinology and Metabolism 201095 E280-E290. (https://doi. org/10.1210/jc.2010-0441)

26 Salehi F, Scheithauer BW, Kovacs K, Horvath E, Syro LV, Sharma S, Manoranjan B \& Cusimano M. O-6-methylguanine-DNA methyltransferase (MGMT) immunohistochemical expression in pituitary corticotroph adenomas. Neurosurgery $201270491-496$; discussion 496. (https://doi.org/10.1227/NEU.0b013e318230ac63)

27 McCormack AI, Wass JA \& Grossman AB. Aggressive pituitary tumours: the role of temozolomide and the assessment of MGMT status. European Journal of Clinical Investigation 201141 1133-1148. (https://doi.org/10.1111/j.1365-2362.2011.02520.x)

28 Hegi ME, Diserens AC, Gorlia T, Hamou MF, de Tribolet N, Weller M, Kros JM, Hainfellner JA, Mason W, Mariani L et al. MGMT gene silencing and benefit from temozolomide in glioblastoma. New England Journal of Medicine 2005352 997-1003. (https://doi. org/10.1056/NEJMoa043331)

29 Walter T, van Brakel B, Vercherat C, Hervieu V, Forestier J, Chayvialle JA, Molin Y, Lombard-Bohas C, Joly MO \& Scoazec JY. O6-methylguanine-DNA methyltransferase status in neuroendocrine tumours: prognostic relevance and association with response to alkylating agents. British Journal of Cancer 2015112 523-531. (https://doi.org/10.1038/bjc.2014.660)
30 Murakami M, Mizutani A, Asano S, Katakami H, Ozawa Y, Yamazaki K, Ishida Y, Takano K, Okinaga H \& Matsuno A. A mechanism of acquiring temozolomide resistance during transformation of atypical prolactinoma into prolactin-producing pituitary carcinoma: case report. Neurosurgery 201168 E1761-E1767; discussion E1767. (https://doi.org/10.1227/NEU.0b013e318217161a)

31 Kil WJ, Cerna D, Burgan WE, Beam K, Carter D, Steeg PS, Tofilon PJ \& Camphausen $\mathrm{K}$. In vitro and in vivo radiosensitization induced by the DNA methylating agent temozolomide. Clinical Cancer Research 200814 931-938. (https://doi.org/10.1158/1078-0432.CCR-07-1856)

32 Carlson BL, Grogan PT, Mladek AC, Schroeder MA, Kitange GJ, Decker PA, Giannini C, Wu W, Ballman KA, James CD et al. Radiosensitizing effects of temozolomide observed in vivo only in a subset of O6-methylguanine-DNA methyltransferase methylated glioblastoma multiforme xenografts. International Journal of Radiation Oncology, Biology, Physics 200975 212-219. (https://doi. org/10.1016/j.ijrobp.2009.04.026)

33 Touma W, Hoostal S, Peterson RA, Wiernik A, SantaCruz KS \& Lou E. Successful treatment of pituitary carcinoma with concurrent radiation, temozolomide, and bevacizumab after resection. Journal of Clinical Neuroscience 201741 75-77. (https://doi.org/10.1016/j. jocn.2017.02.052)

34 Ekeblad S, Sundin A, Janson ET, Welin S, Granberg D, Kindmark H, Dunder K, Kozlovacki G, Orlefors H, Sigurd M et al. Temozolomide as monotherapy is effective in treatment of advanced malignant neuroendocrine tumors. Clinical Cancer Research 200713 2986-2991. (https://doi.org/10.1158/1078-0432.CCR-06-2053)

35 Gilbert MR, Wang M, Aldape KD, Stupp R, Hegi ME, Jaeckle KA, Armstrong TS, Wefel JS, Won M, Blumenthal DT et al. Dose-dense temozolomide for newly diagnosed glioblastoma: a randomized phase III clinical trial. Journal of Clinical Oncology 201331 4085-4091. (https://doi.org/10.1200/JCO.2013.49.6968)

36 Baldari S, Ferrau F, Alafaci C, Herberg A, Granata F, Militano V, Salpietro FM, Trimarchi F \& Cannavo S. First demonstration of the effectiveness of peptide receptor radionuclide therapy (PRRT) with 111In-DTPA-octreotide in a giant PRL-secreting pituitary adenoma resistant to conventional treatment. Pituitary 201215 (Supplement 1) S57-S60. (https://doi.org/10.1007/s11102-011-0373-5)

37 Priola SM, Esposito F, Cannavo S, Conti A, Abbritti RV, Barresi V, Baldari S, Ferrau F, Germano A, Tomasello F et al. Aggressive pituitary adenomas: the dark side of the moon. World Neurosurgery 201797 140-155. (https://doi.org/10.1016/j.wneu.2016.09.092)

38 Komor J, Reubi JC \& Christ ER. Peptide receptor radionuclide therapy in a patient with disabling non-functioning pituitary adenoma. Pituitary 201417 227-231. (https://doi.org/10.1007/s11102-013-0494-0)

39 Maclean J, Aldridge M, Bomanji J, Short S \& Fersht N. Peptide receptor radionuclide therapy for aggressive atypical pituitary adenoma/carcinoma: variable clinical response in preliminary evaluation. Pituitary 201417 530-538. (https://doi.org/10.1007/ s11102-013-0540-y)

40 Waligorska-Stachura J, Gut P, Sawicka-Gutaj N, Liebert W, Gryczynska M, Baszko-Blaszyk D, Blanco-Gangoo AR \& Ruchala M. Growth hormone-secreting macroadenoma of the pituitary gland successfully treated with the radiolabeled somatostatin analog (90) Y-DOTATATE: case report. Journal of Neurosurgery 2016125 346-349. (https://doi.org/10.3171/2015.6.JNS15363)

41 Molitch ME. Diagnosis and treatment of pituitary adenomas: a review. JAMA 2017317 516-524. (https://doi.org/10.1001/ jama.2016.19699)

42 Baldeweg SE, Pollock JR, Powell M \& Ahlquist J. A spectrum of behaviour in silent corticotroph pituitary adenomas. British Journal of Neurosurgery 200519 38-42. (https://doi. org/10.1080/02688690500081230)

43 Jouanneau E, Wierinckx A, Ducray F, Favrel V, Borson-Chazot F, Honnorat J, Trouillas J \& Raverot G. New targeted therapies in 
pituitary carcinoma resistant to temozolomide. Pituitary $2012 \mathbf{1 5}$ 37-43. (https://doi.org/10.1007/s11102-011-0341-0)

44 Hagen C, Schroeder HD, Hansen S, Hagen C \& Andersen M. Temozolomide treatment of a pituitary carcinoma and two pituitary macroadenomas resistant to conventional therapy. European Journal of Endocrinology 2009161 631-637. (https://doi.org/10.1530/EJE-09-0389)

45 Brown RL, Muzzafar T, Wollman R \& Weiss RE. A pituitary carcinoma secreting TSH and prolactin: a non-secreting adenoma gone awry.
European Journal of Endocrinology 2006154 639-643. (https://doi. org/10.1530/eje.1.02141)

46 Lania AG, Ferrero S, Pivonello R, Mantovani G, Peverelli E, Di Sarno A, Beck-Peccoz P, Spada A \& Colao A. Evolution of an aggressive prolactinoma into a growth hormone secreting pituitary tumor coincident with GNAS gene mutation. Journal of Clinical Endocrinology and Metabolism 201095 13-17. (https://doi. org/10.1210/jc.2009-1360)

Received 6 November 2017

Revised version received 19 December 2017

Accepted 8 January 2018 